\title{
46. Biolistic Delivery of Foreign DNA or Genomic Transcripts of Plant Virus Full-length cDNA Clones into Monocotyledonous and Dicotyledonous Plant Tissues
}

\author{
By Chuji HiRuki, ${ }^{*)}$ Hideo KaKuTA, **) Yasuyuki Hashidoko, **) \\ Zhongming GE, *) Gina Figueiredo, *) \\ and Junya MizUTANI**),***)
}

(Communicated by Naohide HiratsukA, M. J. A., Nov. 12, 1993)

\begin{abstract}
Using an improved particle gun driven by compressed nitrogen gas (20 $\mathrm{kg} / \mathrm{cm}^{2}$ pressure), embryos of oat (Avena sativa) and wheat (Triticum aestivum) or primary leaves of cowpea (Vigna unguiculata) were bombarded with gold particles coated with the vector DNA, pBI121, or genomic transcript RNAs of sweet clover necrotic mosaic virus (SCNMV). GUS gene expression in the oat seedlings was detected in the apical meristems of the primary and emerging lateral roots, and in the root hairs, procambium, stele, coleoptiles, phloem elements, and leaf tissues. However, the retention of the foreign gene in the engineered plants was transient and the gene was lost in the absence of Kanamycin stress. With genomic transcipts of SCNMV full-length cDNA clones of $5 \mathrm{ng}$ per bombardment, replication of the delivered genomic viral transcripts was supported by intact primary leaves of cowpea.
\end{abstract}

Key words: Particle gun; biolistic transformation; GUS gene expression; dianthovirus.

Introduction. Genetic transformation of plants provides a powerful tool for the study of gene function and regulation. Molecular procedures for producing transgenic plants include Agrobacterium-mediated transformation, electroporation, microinjection, and protoplast fusion. The successful application of microprojectile bombardment (Christou et al., 1988; Klein et al., 1987, 1988a and b) has expanded the scope of transformation not only into plant species that previously could not be transformed or were difficult to transform by means of Agrobacterium-mediated systems, but also into subcellular organelles such as chloroplasts and mitochondria (Boynton et al., 1988; Johnston et al., 1988). Using this biolistic method, foreign DNA or RNA is successfully delivered into plant tissues (Morikawa et al., 1989; Kakuta et al., 1992; Hiruki et al., 1992; Garzón-Tiznado et al., 1993). The particle gun used in this study is driven by pressure-controlled nitrogen gas and accelerated from above, and foreign DNA or RNA is easily delivered into intact seedlings or plants. Thus, the particle bombardment method makes it possible to deliver foreign genes into seed embryos or apical tissues of intact plants. Furthermore, using this method, it is possible to observe expression of delivered genomes as early as 1-3 days after bombardment. In this study, biolistic transformation of some monocotyledonous crops was attempted. Also reported here are the results on the

*) Department of Plant Science, University of Alberta, Edmonton, Alberta, Canada T6G 2P5.

**) JRDC Plant Ecochemicals Project, Eniwa Research Business Park, Eniwa, Hokkaido 061-13, Japan.

***) Department of Agricultural Chemistry, Hokkaido University, Sapporo, Hokkaido 060, Japan. 
efficient delivery of specific genomic transcripts of the full-length cDNA clones of plant viral genomes into intact leaf tissues of leguminous plants.

Materials and methods. Plant material and plasmid DNA. Oat (Avena sativa) and wheat (Triticum aestivum) seeds were soaked in running tap water for 2 days. The seeds were sterilized in $0.5 \% \mathrm{NaClO}_{3}$ for $10 \mathrm{~min}$ and then in $70 \%$ ethanol for $5 \mathrm{~min}$, rinsed well with sterile water and placed onto $1 \%$ agar plates ( $c a .5 \mathrm{~mm}$ thick, $7-8$ seeds per plate). Thie DNA-delivered seeds were incubated in sterile plastic pots for an $18 \mathrm{hr}$ photoperiod $\left(28^{\circ} \mathrm{C}\right)$ for 10 days. Plants at the three-leaf stage were used for the assay. The plasmid pBI121, which carries the $\beta$-glucoronidase (GUS) gene controlled by the cauliflower mosaic virus (CaMV) 35S promoter region, was purchased from Clonetech Lab. Inc. (Palo Alto, CA, U.S.A.).

Chenopodium quinoa plants and cowpea (Vigna unguiculata cv. California Black Eye) were grown in a sterilized soil mixture (loam, peat, sand; 3:2:1, v/v/v) in peat-molded pot $(10 \times 10 \mathrm{~cm})$ in the greenhouse at $22-25^{\circ} \mathrm{C}$ and were used as described previously (Hiruki et al., 1992).

Construction and generation of infectious SCNMV transcripts. The complete nucleotide sequences of sweet clover necrotic mosaic virus (SCNMV) RNA-1 and RNA-2 have been published (Ge et al., 1992, 1993). The full-length cDNA clones of viral RNAs were constructed by PCR (polymerase chain reaction) (Ge and Hiruki, 1993). The $5^{\prime}$ - and 3 '-nucleotide sequences of the selected RNA-1 and RNA-2 clones were determined by the dideoxy termination method (Sanger et al., 1980). In vitro transcripts of SCNMV genomic RNAs were produced and demonstrated to be infectious (Ge and Hiruki, 1993).

Particle gun and evaluation of gene delivery. The device used in this study was the same as described in the previous report (Hiruki et al., 1992). The bombardments were done at a pressure of $100 \mathrm{~nm} \mathrm{Hg}$, produced by compressed nitrogen gas $\left(20 \mathrm{~kg} / \mathrm{cm}^{2}\right)$, and at a distance of approximately $5 \mathrm{~cm}$ from the stopper to the plant samples.

Gold particles $(0.78 \mu \mathrm{m}$ in diameter) coated with plasmid DNA (300 ng DNA/75 $\mu \mathrm{g}$ gold particles) or transcript RNAs of the full-length cDNA clones of SCNMV (5 ng RNA/75 $\mu \mathrm{g}$ gold particles) by co-precipitation in ethanol, were placed over the macroprojectile and dried in vacuo. The bombardment was done three times in each plate containing the water-absorbed seeds, or once per half-leaf of cowpea primary leaves.

Assay for GUS activity. To detect the GUS activity-positive region, whole seedlings were soaked in an X-Gluc solution $(10 \mathrm{ml})$ which had been filtered through a membrane filter $(0.22 \mu \mathrm{m})$ and incubated at $37^{\circ} \mathrm{C}$ for $18-24 \mathrm{~h}$. The GUS-positive tissues were found to be stained a deep blue color. Hand sections from the roots and shoots were observed under a microscope.

Virus assays. Crude juice was obtained by grinding a leaf disc, $15 \mathrm{~mm}$ diameter, per sample with a mortar and pestle in the presence of $0.025 \mathrm{M}$ phosphate buffer $\left(\mathrm{Na}_{2} \mathrm{HPO}_{4}-\mathrm{NaH}_{2} \mathrm{PO}_{4}\right), \mathrm{pH} 7.0$ at a fixed ratio. The extracts were divided into two portions and used for infectivity assays on Chenopodium quinoa and for ELISA (Hiruki et al., 1984).

Results and discussion. Following the delivery of the pBI121 plasmid, GUS-positive cells were found in the roots, coleoptiles, and first leaves of the oat seedlings (Figs. 1a-d). The apical meristems and procambiums of the primary and lateral roots where the CaMV $35 \mathrm{~S}$ promoter was actively repressed were uniformly stained a deep blue. In the primary root tissues, GUS gene expression was highly active in the stele, lateral meristem, phloem elements, and root hairs (Figs. 2a-c). These results suggest that the foreign DNA was successfully delivered onto several layers of embryo cells which are destined to differentiate into the primary roots, coleoptiles, and the first leaves. The coleoptile and leaf sheath of a first leaf were positively stained, but leaf primordia of second and third leaves 
[Vol. 69(B),

were not stained (Figs. 2d, e). The cells destined to become shoot apices and leaf primordia in the second and third leaves in the embryo were probably too deeply situated for the microprojectiles to reach under the given physical parameters.

Most of the pBI121-delivered wheat seeds did not grow under the same conditions as

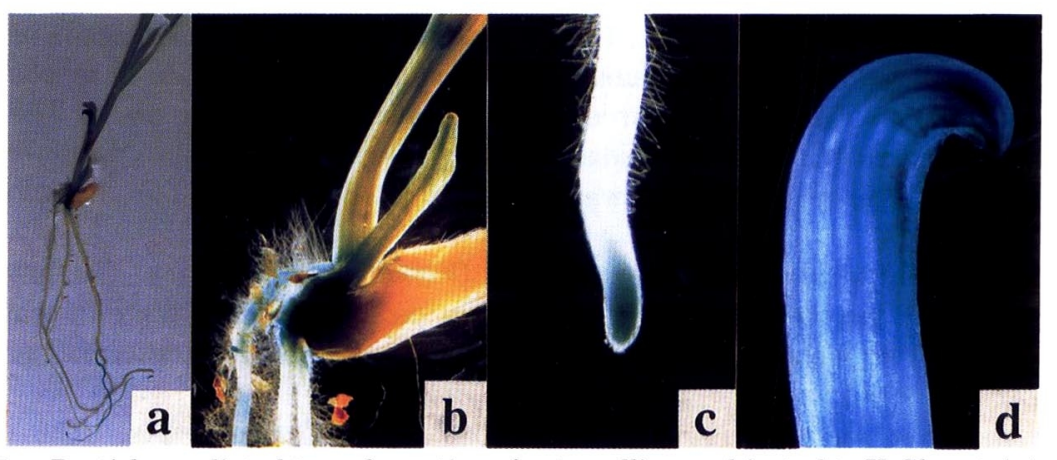

Fig. 1. Particle-mediated transformation of oat seedlings subjected to X-Gluc staining. a, whole seedling: both aerial and root tissues showing GUS activity. b, part of coleorhiza. $c$, root apex. d, tip of coleoptile.
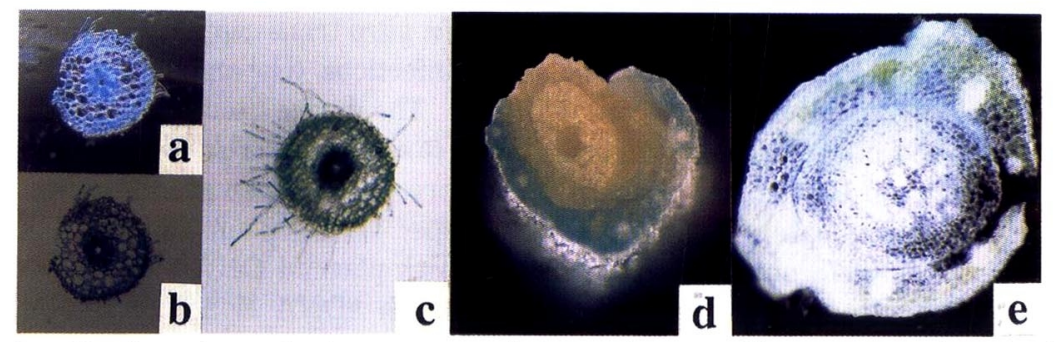

Fig. 2. Hand sections of primary root and shoot of oat seedlings. a, a section of primary root in dark field: both stele and lateral meristem showing GUS activity. b, a section of primary root in bright field. c, a section of primary root in bright field; root hairs clearly showing GUS activity. d, a section of shoot in dark field; coleoptile and leaf sheath of the first leaf are positively stained, but leaf primordia of second and third leaves are not stained. e, a section of shoot decolored with $70 \%$ ethanol.
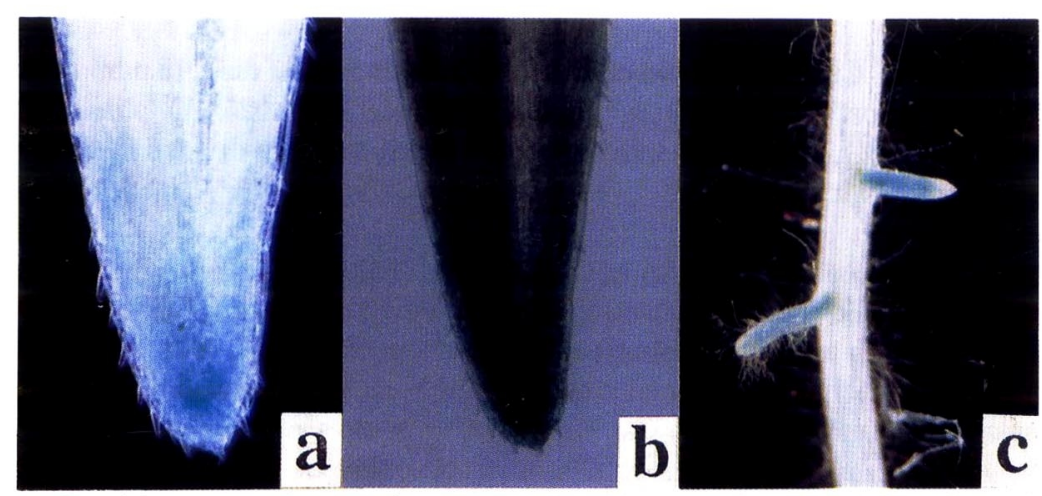

Fig. 3. Particle-mediated transformation of wheat seedlings subjected to X-Gluc staining. a, tip of third leaf in dark field. b, a third leaf in bright field. c, emerging lateral roots; the apical menstems are stained positively. 
those of oat. The seedlings surviving after the bombardment were subjected to the GUS assay, and only some limited positive results were found (Figs. 3a-c). Without Kanamycin stress, the chimeric transformations lost most of the foreign gene before harvest. Nevertheless, our results provide evidence suggesting that the CaMV-35S promoter and the $\beta$-glucoronidase gene can function as a reporter gene system in studying transformation of monocotyledonous species.

In experiments using RNA-1 and RNA-2 transcripts of dianthovirus SCNMV, positive replication resulted only from a sample containing both RNA-1 and RNA-2 transcripts, and this was confirmed by infectivity tests and ELISA. The optimal concentration of RNA for this method was found to be approximately $5 \mathrm{ng}$ per bombardment. Although this study is preliminary in nature, the results obtained so far indicate that genome delivery by means of a particle gun is simple and highly efficient. An attempt to utilize this technique for transformation studies using plant viruses as gene vectors is in progress.

\section{References}

Boynton, J. E. et al. (1988): Science, 240, 1534-1538.

Christou, P. et al. (1988): Plant Physiol., 87, 671-674.

Garzón-Tiznado, J. A. et al. (1993): Phytopathology, 83, 514-521.

Ge, Z. et al. (1992): J. Gen. Virol., 73, 2483-2486.

Ge, Z. et al. (1993): Virus Res., 28, 113-124.

Ge, Z., and Hiruki, C. (1993): Proc. Japan Acad., 69B, 113-118.

Hiruki, C. et al. (1984): Phytopathology, 74, 482-486.

Hiruki, C. et al. (1992): Proc. Japan Acad., 68B, 183-186.

Johnston, S. A. et al. (1988): Science, 240, 1538-1541.

Kakuta, H. et al. (1992): Proc. 1992 Miami Bio/Technol. Winter Symposium, p. 21.

Klein, T. M. et al. (1987): Nature, 327, 70-73.

Klein, T. M. et al. (1988a): Proc. Natl. Acad. Sci. U.S.A., 85, 4305-4309.

Klein, T. M. et al. (1988b): Bio/Technology, 6, 559-563.

Morikawa, H. et al. (1989): Appl. Microbiol. Biotechnol., 31, 320-322.

Sanger, F. et al. (1980): J. Mol. Biol., 143, 161-168. 